\title{
Anabases
}

ANABASES Traditions et réceptions de l'Antiquité

$2 \mid 2005$

Varia

La Métamorphose des ruines. L'influence des découvertes archéologiques sur les arts et les lettres (1870-1914)

\section{Véronique Krings}

\section{(2) OpenEdition \\ Journals}

Édition électronique

URL : http://journals.openedition.org/anabases/1551

DOI : 10.4000/anabases. 1551

ISSN : 2256-9421

Éditeur

E.R.A.S.M.E.

Édition imprimée

Date de publication : 1 octobre 2005

Pagination : 254-256

ISSN : 1774-4296

\section{Référence électronique}

Véronique Krings, "La Métamorphose des ruines. L'influence des découvertes archéologiques sur les arts et les lettres (1870-1914) », Anabases [En ligne], 2 | 2005, mis en ligne le 01 octobre 2011, consulté le 22 septembre 2020. URL : http://journals.openedition.org/anabases/1551 ; DOI : https://doi.org/

10.4000/anabases.1551

Ce document a été généré automatiquement le 22 septembre 2020.

(c) Anabases 


\title{
La Métamorphose des ruines. L'influence des découvertes archéologiques sur les arts et les lettres (1870-1914)
}

\author{
Véronique Krings
}

\section{RÉFÉRENCE}

La Métamorphose des ruines. L'influence des découvertes archéologiques sur les arts et les lettres (1870-1914), Actes du colloque international organisé à l'École française d'Athènes (27-28 avril 2001), édités par Sophie BASCH, Athènes, École française d'Athènes, 2004, 192 p., XXIX planches.

60 euros / ISBN 2-86958-174-2

1 Ce volume, qui réunit les contributions d'un colloque qui s'est tenu à l'École française d'Athènes les 27 et 28 avril 2001, n'a rien d'inaugural, comme le rappelle dans l'introduction S. Basch, dans la mesure où il s'inscrit « dans la continuité de recherches qui ont tendu à revaloriser les manifestations artistiques inspirées par l'Antiquité et par l'archéologie, variations parfois taxées, avec désobligeance, de vulgarisations, alors même qu'elles étaient fort érudites et exigeaient une grande sensibilité esthétique ». Devant la diversité et l'ampleur des domaines à explorer, l'organisatrice a fait le choix judicieux d'apporter deux limites aux travaux de ce colloque. D'une part, le cadre temporel a été restreint aux années 1870-1914, qui, entre deux cataclysmes, furent marquées par un grand bouillonnement dans les mondes de l'archéologie et de l'art. D'autre part, c'est la seule Grèce, telle qu'elle est perçue au tournant des $\mathrm{xIX}^{\mathrm{e}}$ et $\mathrm{xx}^{\mathrm{e}} \mathrm{s}$., qui a été retenue. La période prise en compte est en fait très stimulante, car, dans le même temps où l'archéologie, en tant que méthode d'investigation, se constitue, on assiste à une polémique - la France de la Troisième République ayant été 
particulièrement affectée - autour de la redistribution des disciplines, particulièrement à une certaine opposition entre Histoire et littérature (au sens large). Le choix de la Grèce est également intéressant, puisque, tandis que son statut politique - « un pays qui représenta pendant des siècles une patrie mentale » - évolue, la découverte de la Grèce archaïque, byzantine, médiévale «oblige à diversifier un regard jusqu'alors étrangement fixe ». Par ailleurs, si c'est au nom du lien unissant les lettres, les arts et l'archéologie grecque qu'avait été créée l'École française d'Athènes, première institution scientifique étrangère en Grèce, sa mission de recherche, relayant la vocation artistique initiale, ne s'affirma de façon décisive qu'après la défaite de 1870 , dans un esprit de revanche sur la savante Allemagne.

2 Quel a été l'impact sur les écrivains et artistes d'une nouvelle approche de l'Antiquité ? Quels usages en firent-ils? Quel écho l'archéologie eut-elle en dehors de la science? A. Farnoux ouvre le débat sur l'évolution du travail des archéologues et analyse la diffusion de celui-ci en France ainsi que son impact sur le changement du regard des contemporains sur les ruines. À partir des reconstitutions graphiques des monuments préhistoriques, O. Polychronopoulou démontre qu'elles illustrent non seulement les idées de leurs inventeurs mais constituent aussi une trace des mentalités, d'un contexte et d'une époque précis ; par leur diffusion, elles ont aussi contribué à l'émergence d'un autre regard vis-à-vis des Mycéniens et des Minoens. L'effroi suscité par la découverte des idoles cycladiques a retenu V.Chryssovitsanou: c'est seulement lorsque la protohistoire égéenne a gagné du terrain que ces trouvailles ont été étudiées plus scientifiquement, l'idéal de la Grèce classique n'ayant dans un premier temps laissé aucune place aux approches divergentes. P. Tournikiotis s'attache à deux ouvrages majeurs relatifs à l'histoire et à la théorie de l'architecture parus au tournant des XIXe et $\mathrm{xx}^{\mathrm{e}} \mathrm{s}$. (A. Choisy et J. Guadet) ; il s'interroge sur la manière dont la "Grèce des ruines " s'est impliquée dans le discours sur la création architecturale, à travers l'exemple de l'ordre dorique et en particulier du Parthénon. À partir des revues d'archéologie et d'histoire de l'art, J.-C. Mossière analyse finement l'utilisation des images dans la construction de la science archéologique, dans la mise en scène de la présentation des objets et dans la diffusion des connaissances. La vogue des Tanagras, exhumées à partir de 1872, fut rapide et durable; au départ, accessoires de la décoration, elles sont réinvesties par les artistes de significations nouvelles: C.Peltre étudie les métamorphoses dont les figurines sont l'objet, s'attachant aux correspondances entre le discours scientifique et les variations artistiques, éclairant par ce biais le rôle de l'archéologie. G. Tolias examine les notions de «civilisation helléno-chrétienne » et d'«hellénicité " et leurs implications dans les sciences humaines, la langue, la littérature ainsi que dans la réflexion politique. Théophile Gautier et la Vénus de Milo l'écrivain lui consacre un article en 1871 -, ou la redécouverte d'une statue grecque dans les aléas de 1870, telle est la thématique abordée par P. Tortonese, qui par ce biais éclaire les échanges chez Gautier entre archéologie, histoire et littérature. Le retour de Byzance dans les études scientifiques va entraîner l'apparition d'une nouvelle Byzance dans l'art, débouchant sur une réelle byzantinomanie, comme le montre S. Basch, à travers la Théodora de V. Sardou. J.-Y. Masson montre comment d'une fuite, le voyage de Hofmannsthal en Grèce en 1908 s'est transformé en une initiation, celui-ci ayant rencontré sur le sol grec une autre idée de la Grèce que celle diffusée par la formation classique qui avait été la sienne. V. Deshoulières se penche sur H. Schlieman et particulièrement sur la réception jusqu'à nos jours de l'archéologue devenu un personnage littéraire, depuis que lui-même avait raconté sa vie (Leipzig, 1881) et que 
Freud plaça sous sa tutelle l'analogie entre psychanalyse et archéologie. Enfin, Y. Lenoir étudie l'influence que la musique grecque exerça sur les musiciens d'Europe occidentale. Au total, douze contributions nous sont proposées qui apportent autant de réponses et ouvrent autant de pistes. Un programme similaire pourrait en effet, avec intérêt sûrement, être appliqué à d'autres tranches chronologiques ou à d'autres espaces. Aux résultats et réflexions d'archéologues, de littéraires et d'historiens de l'art que rassemble ce volume, on ne peut que souhaiter que se joignent aussi celles des historiens pour qui le thème retenu est également marquant dans l'évolution de leur discipline et des conditions politiques, économiques et sociales de sa pratique, de même que dans la perception de l'Antiquité. Un volume donc stimulant, à l'édition très soignée, intégrant une présentation des contributeurs, des résumés des communications en trois langues et une trentaine de planches de belle qualité.

\section{AUTEUR}

\section{VÉRONIQUE KRINGS}

Université de Toulouse II-Le Mirail

vkrings@wanadoo.fr 